\title{
Enterprise Information Space in the Transition to an Innovative Economy
}

\author{
N.V. Molotkova ${ }^{1}$, M.N. Makeeva ${ }^{1}$ and D.L. Khazanova ${ }^{1, *}$ \\ *Corresponding author: khazanova@ya.ru \\ ${ }^{1}$ Tambov State Technical University, Tambov, Russia
}

\begin{abstract}
The present stage of development of our country is distinguished by dynamism and qualitative changes in all spheres of public life. As the information component of the modern economy grows in Russia, the role and importance of the information interaction of an enterprise with representatives of the internal and external business environment increases significantly, and this has a direct impact on the effective functioning of the organization at all stages of its production, sales and management activities. Properly organized processes of receiving, storing, processing and analyzing data within the organization allow us to assess the company state of affairs, plan for the nearest future and assess future prospects, make timely decisions about changing of business policies, reorganizing the structure, timely fulfillment of sales and production plans, and effectively use the employees' working hours with the greatest benefit to the organization.

The set of information flows that ensure an organization interaction with its internal and external representatives forms the information space of the enterprise.
\end{abstract}

Keywords: the information space of the enterprise, information flows.

\section{Introduction}

The study of modern theoretical approaches to the definition of the information space of the organization, its properties, functions and structure is due to the significant influence of information interaction on the efficiency of industrial enterprise management. In this regard, the objective necessity of introducing the concept of the enterprise information space is substantiated.

The information space of an enterprise should be understood as the totality of information flows that form a special environment in an enterprise's activity [1]. It is characterized by movement and transmission of information about an enterprise, considered in the course of its perception, and supporting informational interaction between company employees and interaction of the company with its external customers. The components of the information space are information resources, information interaction tools and technologies, an information infrastructure.

\section{Problem Statement}

The key goal of creating and maintaining an effective information space in an organization is to ensure the interaction of the company's existing information flows and to provide all users with information on a convenient basis, according to their interests and these of the organization as a whole.

Timely receipt of necessary and reliable information, access to the regulatory framework, the availability of streamlined channels of information exchange - all this is necessary for the effective functioning of the organization information space. Optimization and "transparency" of business processes [2], development of intracorporate standards, regulations, formalization of connections, identification of "points of failure" (the causes of slowing down or distortion of information transmission), ensuring information security contribute to the establishment of enterprise information interaction with its internal and external representatives.

\section{Research Questions}

The information space of the enterprise is the most dynamic element of the internal environment. The qualitative rethinking of methods and technologies of information space management has a significant impact on the result of the company as a whole, which confirms the special significance of studying of the information space impact on an enterprise management. In this paper, the authors focus their attention on the information space as an object of control. 


\section{Purpose of the Study}

The purpose of the study is to reveal the concept of the enterprise information space, as well as to determine its prerequisites for the formation, development and influence on the internal and external sides of the enterprise. The paper focuses on defining the set of information flows that ensure an organization interaction with its internal and external representatives.

\section{Research Methods}

In conducting this study, methods of a systematic approach, structural and functional analysis, expert assessments and forecasting, content analysis of scientific literature, as well as monographic, abstract, logical, and other methods of economic research were applied. Combined methodological approach allowed the authors to structure the process of study both on theoretical and practical levels.

\section{Findings}

Currently, the exact scientific wording of the term "information space" is not proposed, although this concept is used quite extensively in various connotation interpretations, but its interpretation as a scientific definition is poorly studied.

In 1995, the "Concept of Formation and Development of the Unified Information Space of Russia and Relevant State Information Resources" was adopted, which is one of the most important documents for creating a state information policy. In this concept, the structure of the information space is marked as an extremely complex paradigm, consisting of the following elements:

- information resources represented by databases and data banks, a system of depositories of state information resources, libraries, etc.;

- $\quad$ information and telecommunication infrastructure [3];

- media systems;

- market of information technologies represented by means of communication, information and telecommunications, information products and services;

- $\quad$ information security systems;

- $\quad$ systems of interaction of the information space of Russia with the global open networks;

- information legislation systems [4].

Considering the above, the information space can be interpreted as a complex systemic phenomenon, which can be studied by resorting to a systematic approach.

According to the author, this definition does not take into account the need for a substantive orientation of the information space, which leads to its spontaneous organization. Also, this interpretation does not reflect the need to organize systems for analytical processing and presentation of information in a form convenient for different groups of users.

The information space can be defined as "the interaction of people expressed by spatial characteristics". "At the personal level, knowable distances become the basis for making individual decisions in spatial interaction. For research purposes, the use of generalized models becomes, by definition, a peculiar measure of the distance over which all interactions of individuals are distributed depending on time, cost, others, any complicated relationship between origin and goal of interaction "[5].

Studying the versatility of the concept of "information space" one should not forget about such properties of objects and interaction processes as their intensity, orientation, density and volume. These aspects play a significant role in information management. At the same time, the essential difference of the information space as a form of social interaction from other types of space is that its appearance and further development is completely associated with the activity of the social subject - the society as a whole, the social group or an individual [6].

Information space is a territory "covered" by information, information resources and infrastructure, within which all subjects have the same possibilities of receiving, transmitting and various manipulations with information at any point of this space. It should also be noted that the information product in this interpretation is understood as documented information prepared according to the user's needs and used to meet the user's needs, and the concept of "information services" is interpreted as actions of subjects (owners) aimed at providing the user with information products.

Information space is rationally interpreted as a type of space formed on the basis of endogeneity recognition of the production information factor, including the relations of economic entities about this factor as well as the corresponding conditions, resources and products of their activities. The use of the structural approach in the description of the microlevel economic system makes it possible to form an internal information system at various levels that reflects all elements of their internal environment.

Information space is the space in which information is created, moved and consumed. The information space of an enterprise forms information flows that are formed when an enterprise occurs without special manipulations. 
Information flow is a set of information that moves in the information space through communication channels. At a certain point in time, there is a need for managing and analyzing the organization's information flows in order to improve, develop and control the relationship between the enterprise and its environment, both internal and external [7].

Regarding the organization, the "information space" is viewed as an aggregate of people and information that they exchange and that they perceive in the process of interpersonal interaction, as well as social relations formed due to information exchange and informational influence on human consciousness.

Emphasizing the importance of the major information flows formed and subject to operational management by the organization, such as: sales and accounting of inventories (accounting information system), production process (production accounting information system), cash flow and fixed assets of an enterprise (accounting and tax information system) etc. It is appropriate in the course of creating the information space to combine the first three types of information flows with the necessary flows from the category "minor" (information about competitors: product range, price, production volume and sales, applied databases and other internal information).

On this basis, management acquires a decision support system, which makes it possible to obtain the maximum amount of timely and important information, operating within a single information space. In the case of integration of the visual interface and automated reporting system, as well as the use of information technology, the user has the opportunity to use analytical data in the online mode. Along with this, the information basis for making operational management decisions is information that is accumulated, processed and analyzed in various departments of the organization that receive information from internal and external sources [8]. Having considered various approaches to the definition of the term "information space", we proposed the following wording:

The information space of an enterprise is a set of information flows that form a special environment in the enterprise activity, which is characterized by the movement and transmission of information about the enterprise, considered in the course of its perception, and supporting:

- informational interaction of company employees;

- informational interaction of the company with external customers;

- information needs of employees and representatives of the external environment of the company satisfaction.

Information space management is an important condition for the formation, development of the organization and attracting the necessary attention from the main external clients. A competent approach to the management of information space will allow the manager to implement the basic functions of information in the company:

- Economic function. It manifests itself, first of all, in providing internal customers with relevant information about various financial operations and processes that take place in the company, namely production, purchase of inventory, sales of ready products, sales promotion, sales, etc.

- Management function. Possession of the necessary information makes it possible for managers at various levels to make correct management decisions, which, in turn, enables to prevent serious management errors and deviations from the optimal functioning of the company.

- Monitoring function. This function is directly related to management. Reporting information allows you to assess the business processes of the company in order to match their goals and objectives, and in addition, to change and improve the management methods and technology in the event of inconsistencies.

- Communication function. It is manifested in maintaining both direct communication and feedback with the market and external customers through various media activities on the part of the organization. Managers implement this function through PR-tools, advertising and marketing communications (BTL).

- Demand management function. Using information, managers implement the function of sales management, which allows you to stimulate sales organization and sales. This function is realized when using communication tools in order to influence consumer's consciousness.

- Image function. Information about the company, its main areas of activity, economic indicators, compensation package provided to organization employees, products or services provided - all this range of data forms in the minds of consumers and other external customers a certain view (image) of the company. A large number of information circulates in each firm, which can have both constructive and destructive impact on its reputation therefore forming a positive image of the company in the market is one of the key tasks of managing the information space.

Another important aspect for maintaining the normal functioning of information flows in a company is the problem of creating such a space that would provide an opportunity to all internal customers of an enterprise in various areas of the company's work to freely form and use information - a single information space [9].

To maintain a high level of quality of the company's information space, all information must comply with a number of characteristics, which will allow the organization to effectively manage both internal and external information flows. Relevance, completeness, accessibility, reliability, timeliness, security and ergonomics of information are usually considered among its main properties.

The regulation of information flows of an organization is an integral part of managing the information space of an organization, which, in turn, is an important component in its management activities. Inadequate or untimely awareness of the subjects of management and employees of the organization, lack of access to information resources of the enterprise and other information limitations reduce the effectiveness of management decisions, which may result in the organization lagging behind in innovation and damage its reputation and financial condition in general. 


\section{Conclusion}

Under a single information space, we understand a set of databases and banks of information, technologies of their management and application, information and telecommunication systems and networks that operate according to common principles and rules of work and provide information interaction between workers and enterprises, and, moreover, satisfy their information needs. Having created a single information space, the company has a chance to implement the above functions and use the entire available array of information in the most convenient and automated way.

The main characteristics of a single information space (SIS):

A single information space of the company is based on the latest advanced developments and allows for scalability and good integration capabilities, as a result, the implementation of business applications, such as electronic document management, automated accounting systems, corporate portals, etc. can be greatly facilitated.

Implementing SIS provide an organization the opportunity to geographically expand its business and integrate branches into a single collection of applications where employees can simultaneously obtain the information they need, by providing them with remote corporate access.

A single information space can be maintained and managed centrally (all equipment and software in the branches is supported by remote configuration), which enables to reduce infrastructure maintenance costs, predict them, and improve the timeliness of solving industrial incidents.

All organization's information resources without exception reside on the central office server, in respect of which work is constantly being done to prevent unauthorized access, backup, and anti-virus protection, thus reducing the likelihood of loss of information that is significant to the enterprise, illegal access to it and maintaining stable the work of the organization's information system. Even without the introduction of specialized business applications, using the IT infrastructure of the basic option, the company has the opportunity to distinguish between the rights of access to the database, and its employees can use corporate email, a shared network drive, centralized anti-virus protection, firewall and other infrastructure capabilities [10].

Consequently, the main goal of creating and maintaining an effective information space in an organization is to ensure the interaction of the company's existing information flows and to provide all users with information on a convenient basis, according to their interests and the organization as a whole.

\section{References}

1. D. Perani, S. Sirilli, Benchmarking innovation in European countries. Forsyth, 2(1), 4-15 (2008). [in Rus.].

2. I.A. Volnov, Methodology for creating a single information space of an enterprise. Symbol of Science, 2(4), 46-48 (2017). [in Rus.].

3. V.G. Prudsky, Russian model of modern management as a national competitive advantage. Economy of the region, 3, 114-119 (2009). [in Rus.].

4. A.V. Dorofeev, A.S. Markov, Information security management: Basic concepts. Cybersecurity Issues, 1(2), 67-73 (2014). [in Rus.].

5. V.V. Muromtsev, New management paradigm in complex organizational systems (introduction to information management). Economic Journal, 4(32), 143-150 (2013). [in Rus.].

6. V.A. Mordvinov, Synergetics in the information field. Prospects of Science and Education, 3(15), 25-31 (2015). [in Rus.].

7. A.V. Taranov, Improving the model and strategies of information management. Bulletin of Bryansk State University, 3, 54-57 (2011). [in Rus.].

8. D.A. Kononov, V.V. Kulba, A.N. Shubin, Information management in socio-economic systems: Information campaigns in the information fields. Management Problems, 4, 81-87 (2004). [in Rus.].

9. L.V. Shaborkina, Problems of management of innovative processes in the enterprise. Bulletin of the University of Mordovia, 1, 3-6 (1996). [in Rus.].

10. A.G. Svetlakov, I.M. Glotina, The impact of the information space on the economic security of the region. Economy of the Region, 2 (14), 474-484. DOI: 10.17059 / 2018-2-11 (2018). [in Rus.]. 